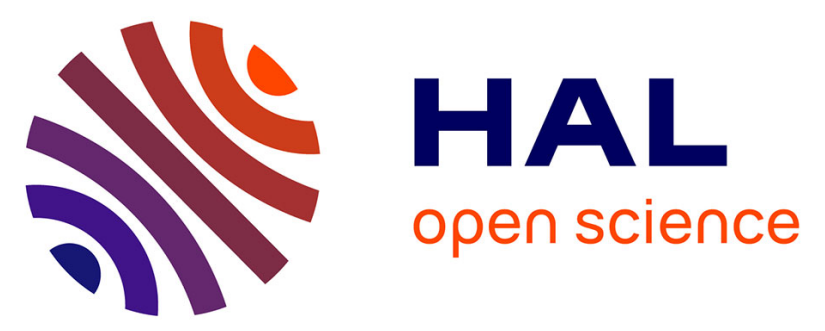

\title{
Experimental study of hydraulic ram effects on a liquid storage tank: Analysis of overpressure and cavitation induced by a high-speed projectile
}

Nicolas Lecysyn, Aurélia Bony-Dandrieux, Laurent Aprin, Frederic Heymes, Pierre Slangen, Gilles Dusserre, Laurent Munier, Christian Le Gallic

\section{To cite this version:}

Nicolas Lecysyn, Aurélia Bony-Dandrieux, Laurent Aprin, Frederic Heymes, Pierre Slangen, et al.. Experimental study of hydraulic ram effects on a liquid storage tank: Analysis of overpressure and cavitation induced by a high-speed projectile. Journal of Hazardous Materials, 2010, 178 (1-3), pp.635643. 10.1016/j.jhazmat.2010.01.132 . hal-02012164

\author{
HAL Id: hal-02012164 \\ https://hal.science/hal-02012164
}

Submitted on 24 Feb 2020

HAL is a multi-disciplinary open access archive for the deposit and dissemination of scientific research documents, whether they are published or not. The documents may come from teaching and research institutions in France or abroad, or from public or private research centers.
L'archive ouverte pluridisciplinaire HAL, est destinée au dépôt et à la diffusion de documents scientifiques de niveau recherche, publiés ou non, émanant des établissements d'enseignement et de recherche français ou étrangers, des laboratoires publics ou privés. 


\title{
Experimental study of hydraulic ram effects on a liquid storage tank: Analysis of overpressure and cavitation induced by a high-speed projectile
}

\author{
Nicolas Lecysyn ${ }^{\mathrm{a}, *}$, Aurélia Bony-Dandrieux ${ }^{\mathrm{a}}$, Laurent Aprin ${ }^{\mathrm{a}}$, Frédéric Heymes ${ }^{\mathrm{a}}$, Pierre Slangen ${ }^{\mathrm{a}}$, \\ Gilles Dusserre ${ }^{\mathrm{a}}$, Laurent Munier ${ }^{\mathrm{b}}$, Christian Le Gallic ${ }^{\mathrm{b}}$ \\ a Ecole des Mines d'Alès, 6, avenue de Clavières, 30319 Alès Cedex, France \\ b Centre d'études de Gramat, Commissariat à l'Energie Atomique, 46500 Gramat, France
}

\section{A B S T R A C T}

This work is part of a project for evaluating catastrophic tank failures caused by impacts with a high-speed solid body. Previous studies on shock overpressure and drag events have provided analytical predictions, but they are not sufficient to explain ejection of liquid from the tank. This study focuses on the hydrodynamic behavior of the liquid after collision to explain subsequent ejection of liquid. The study is characterized by use of high-velocity projectiles and analysis of projectile dynamics in terms of energy loss to tank contents. New tests were performed at two projectile velocities ( 963 and $1255 \mathrm{~m} \mathrm{~s}^{-1}$ ) and over a range of viscosities (from 1 to $23.66 \mathrm{mPa}$ ) of the target liquid. Based on data obtained from a highspeed video recorder, a phenomenological description is proposed for the evolution of intense pressure waves and cavitation in the target liquids.

Keywords:

Hydraulic ram

Catastrophic failure

Cavitation

Risks

\section{Introduction}

During past wars, hydraulic rams were investigated to avoid catastrophic failure of fuel cells in aircraft that were subjected to ballistic impact. In today's geopolitical context, some storage tanks are expected to be targets for terrorists. These atmospheric liquid storage tanks are commonly used in chemical plants, as tanker trucks, and to store gasoline and fertilizers; the failure of such tanks could have serious consequences on the environment, including toxic and flammability effects. Tank failures could be initiated by a high energy burst, leading to an explosion that produces a shockwave and thermal effects.

\subsection{Problem statement}

Catastrophic tank failure was studied during the Apollo space project to understand damage mechanisms that could be induced by meteorites impacting spacecraft fuel cells [1]. Tests were carried out by firing hypervelocity projectiles (from 1301 to $6400 \mathrm{~m} \mathrm{~s}^{-1}$ ) into water tanks. In those studies, researchers were particularly interested in evaluating damage mechanisms caused by hydraulic rams. A hydraulic ram combines a number of events, as illustrated schematically in Fig. 1. (1) When the projectile enters the tank, the tank wall may crack due to the high pressure and stresses

\footnotetext{
* Corresponding author. Tel.: +33 466782766; fax: +33 466782701 . E-mail address: nicolas.lecysyn@ema.fr (N. Lecysyn).
}

near the entry point, and (2) a shock wave is formed. As the projectile traverses the fluid, (3) high pressure is generated, and energy is imparted to the fluid through projectile drag. (4) This energy sets the fluid in motion, forming a cavity. (5) Both the fluid motion and the subsequent cavity growth and collapse impose stresses on tank walls. Finally, if the projectile has sufficient kinetic energy, it will exit the tank. As it exits, (6) a local area of compressed fluid is formed, and (7) cracks are produced in the wall around the exit hole. This phenomenon has been the subject of investigations into survivability of fuel cells in military aircraft [2-6].

This brief description demonstrates the complex physical mechanisms that contribute to a hydraulic ram. Using fluid dynamics and one-dimensional equations of state, it is possible to describe this phenomenon analytically. The present approach is to determine a source term for liquid ejection due to impact on a tank.

\subsection{Theoretical background}

The simplified diagram in Fig. 1 shows three major events contributing to a hydraulic ram: (a) a projectile impacts a tank wall, producing a high-pressure shock wave in the fluid, (b) the projectile traverses the fluid, transferring energy to the fluid and forming a cavity, (c) the projectile exits the tank, compressing fluid near the rear wall and cracking that wall. A complete analytic description of a hydraulic ram requires an analytic characterization of each of these events. 


\begin{tabular}{|c|c|}
\hline \multicolumn{2}{|c|}{ Nomenclature } \\
\hline$A_{c}$ & cavity cross-sectional area $\left(\mathrm{m}^{2}\right)$ \\
\hline$A_{p}$ & $\begin{array}{l}\text { projectile cross-sectional area, for spherical projec- } \\
\text { tile } A_{p}=\pi d_{p}^{2} / 4\left(\mathrm{~m}^{2}\right)\end{array}$ \\
\hline$C_{x}$ & drag coefficient of projectile \\
\hline$C_{x}(0)$ & drag coefficient without cavitation \\
\hline$C_{x}(K)$ & drag coefficient with cavitation \\
\hline$C_{p}$ & sound velocity in projectile material $\left(\mathrm{m} \mathrm{s}^{-1}\right)$ \\
\hline$C_{l}$ & sound velocity in fluid $\left(\mathrm{m} \mathrm{s}^{-1}\right)$ \\
\hline$d_{\max }$ & cavity maximum diameter $(\mathrm{m})$ \\
\hline$d_{p}$ & projectile diameter $(\mathrm{m})$ \\
\hline$g$ & gravitational acceleration $\left(\mathrm{m} \mathrm{s}^{-2}\right)$ \\
\hline$h$ & height of liquid at shot level axis (m) \\
\hline$K$ & cavitation parameter \\
\hline$m_{p}$ & mass of projectile $(\mathrm{kg})$ \\
\hline$m$ & mass of displaced liquid during penetration $(\mathrm{kg})$ \\
\hline$n_{1}, n_{2}$ & refraction indexes of medium 1 and 2 \\
\hline$\mu_{l}$ & fluid viscosity (Pa s) \\
\hline$p_{0}$ & $\begin{array}{l}\text { initial static pressure at axis level of the projectile } \\
(\mathrm{Pa})\end{array}$ \\
\hline$p$ & static pressure at axis level of the projectile $(\mathrm{Pa})$ \\
\hline$p_{v}$ & liquid vapor pressure $(\mathrm{Pa})$ \\
\hline $\operatorname{Re}$ & Reynolds number \\
\hline$r_{c}$ & cavity diameter $(\mathrm{m})$ \\
\hline$\rho_{l}$ & fluid density $\left(\mathrm{kg} \mathrm{m}^{-3}\right)$ \\
\hline$\rho_{p}$ & projectile density $\left(\mathrm{kg} \mathrm{m}^{-3}\right)$ \\
\hline$s_{p}$ & Hugoniot slope coefficient of projectile material \\
\hline$S_{l}$ & Hugoniot slope coefficient of fluid \\
\hline$t$ & time (s) \\
\hline$\theta_{1}, \theta_{2}$ & respectively incident and refractive angles (rad) \\
\hline$u$ & axial growth velocity of cavity $\left(\mathrm{m} \mathrm{s}^{-1}\right)$ \\
\hline$u_{c}$ & radial growth velocity of cavity $\left(\mathrm{m} \mathrm{s}^{-1}\right)$ \\
\hline$u_{p 0}$ & projectile velocity before impact $\left(\mathrm{m} \mathrm{s}^{-1}\right)$ \\
\hline$u_{p}$ & projectile velocity after impact $\left(\mathrm{m} \mathrm{s}^{-1}\right)$ \\
\hline$u_{s}$ & shock front velocity $\left(\mathrm{m} \mathrm{s}^{-1}\right)$ \\
\hline$V_{p}$ & $\begin{array}{l}\text { projectile volume, for a spherical projectile } V_{p}= \\
4 \pi d_{p}^{3} / 3\left(\mathrm{~m}^{3}\right)\end{array}$ \\
\hline
\end{tabular}

\subsubsection{Shock wave}

As described by Holm [3], when a high-speed projectile impacts a tank, dynamic stresses are generated and transmitted through the wall. These stresses are caused by the penetration and perforation and take the form of compressive and circumferential bending stresses in the wall. As the projectile perforates the tank, it accelerates the fluid directly ahead of the impact point: before impact

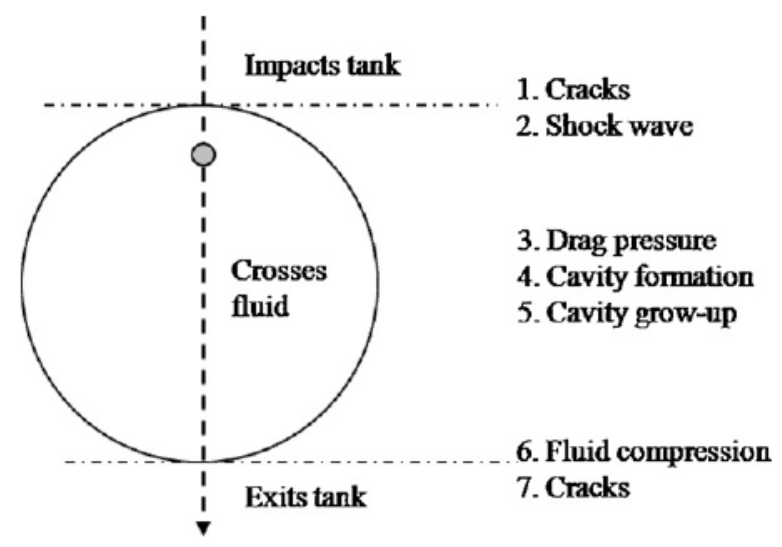

Fig. 1. Proposed sequence of events occurring during a hydraulic ram.

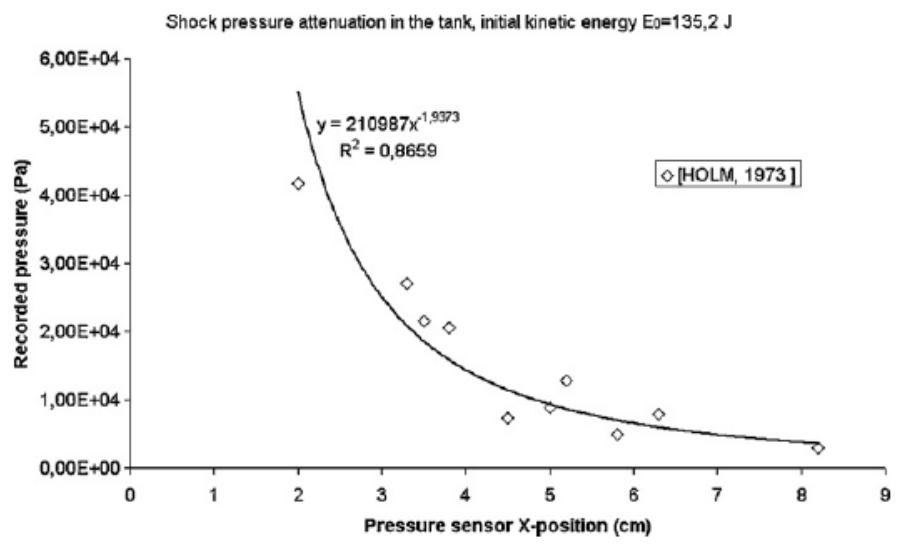

Fig. 2. Rapid decrease in impact shock pressure with distance (adapted from Holm [3]).

the fluid is at rest, but at the instant after impact, the fluid is moving at the velocity of the projectile. This sudden acceleration of the fluid generates an intense pressure field bounded by a shock wave. Tank wall stresses are induced by this pressure field which, when added to this dynamic stresses, can cause catastrophic failure of the entry wall. The shock-wave pressure field expands in a hemispherical shape away from the impact point with a velocity greater than that of sound in the fluid.

Townsend et al. [6] have studied super-velocity impacts on aircraft fuel cells filled with water. They used 3.5 and $7 \mathrm{~g}$ hardened steel, cubic projectiles moving at velocities from 1000 to $3000 \mathrm{~m} \mathrm{~s}^{-1}$; they measured overpressures in the target tank of up to 500 bar. Experimental tanks dimensions were respectively $535 \mathrm{~mm} \times 205 \mathrm{~mm} \times 150 \mathrm{~mm}$ and $423 \mathrm{~mm} \times 320 \mathrm{~mm} \times 250 \mathrm{~mm}$ (height $\times$ width $\times$ depth). They proposed an analytical model that describes shock-wave dynamics, based on the Hugoniot-Rankine relations:

$u_{s}=C_{l}+S_{l} u_{p}$

This relation shows that the velocity $u_{s}$ of the shock front is greater than the speed of sound $C_{l}$ in the fluid.

It is known that both the velocity of the shock front and the intensity of the related pressure field vary directly with the amount of energy that the projectile transfers to the fluid during impact. Borg et al. [7] have performed tests using a $19 \mathrm{~g}$ aluminum projectile impacting a tank filled with tributylphospate; impact velocities varied from 2100 to $4100 \mathrm{~m} \mathrm{~s}^{-1}$. Based on (1), Borg proposed that the impact pressure can be written as

$p=\rho_{l} C_{l} u_{p}+\rho_{l} S_{l} u_{p}^{2}$

Using (2), Borg could compute the velocity drop on impact. Note that (2) relates the shock overpressure to the projectile impact energy $\left(\approx u_{p}^{2}\right)$.

Although the peak pressure at impact is high, the pressure field weakens rapidly because of the geometric expansion of the shock wave. An experimental example of this pressure attenuation is provided by Holm [3] and is shown in Fig. 2. Stepka et al. [1] has studied impacts on tanks which were $61 \mathrm{~cm}^{2}$ by $30.5 \mathrm{~cm}$ or a cube $30.5 \mathrm{~cm}$ on as side. For a $0.9 \mathrm{~g}$ steel cylinder impacting with a velocity of $4270 \mathrm{~m} \mathrm{~s}^{-1}$, Stepka et al. [1] found the pressure to be $4.63 \times 10^{9} \mathrm{~Pa}$ at a distance of $0.019 \mathrm{~m}$ from impact, but the pressure dropped to ambient at $0.13 \mathrm{~m}$ from the impact point. They also found that, for the same time after impact, small high-velocity projectiles lose a larger part of their kinetic energy than more massive, low-velocity projectiles. These results indicate that, even for high-velocity and high-kinetic energy projectiles, the side and rear walls of exper- 
imental tanks are not subjected to significant pressures from the shock wave.

In summary, the shock wave created by a hydraulic ram is characterized by an intense pressure field of short duration ( $100 \mu \mathrm{s})$ compared to the drag pressure phase. It is essentially a "point source" energy release that results in an expanding, hemispherically shaped, pressure wave front that emanates from the point of impact. The kinetic energy of the projectile is the most important parameter in determining the speed of propagation and strength of the shock front. This pressure pulse contributes to tank failure mainly when small high-velocity projectiles impact a storage tank.

\subsubsection{Drag pressure}

Any surface in contact with a flowing fluid is subject to a drag force exerted by the fluid. A force balance shows that this drag force decreases the velocity of the projectile. This problem has been studied by Stepka et al. [1]. They fired super-velocity projectiles into tanks filled with water and measured projectile velocities and fluid pressures at different points in the tank. Then Stepka et al. analyzed the data, starting with Newton's second law in the form

$\rho_{p} V_{p} \frac{d u_{p}(t)}{d t}=-\frac{1}{2} C_{x}(t) \rho_{l} A_{p} u_{p}^{2}(t)$

In (3) the liquid is assumed incompressible and $C_{x}$ is a constant, $A_{p}$ and $V_{p}$ are computed for a spherical body. The solution to (3) is

$u_{p}(t)=\frac{u_{p 0}}{1+\frac{3}{4} C_{x}\left(\rho_{l} u_{p 0} / \rho_{p} d_{p}\right) t}$

This relation describes the decay of projectile velocity; in another words, drag forces dissipate energy from the projectile to the fluid.

Borg et al. [7] assumed that $C_{x}$ is not constant but, instead, varied with time; then they solved (3) numerically using a Runge-Kutta scheme. Moreover, they used the Hugoniot-Rankine relation to quantify the projectile velocity decay. We have computed projectile velocity decay with Borg's approach and have compared it to results computed with Eq. (4) and find no distinguishable differences (less than $2 \%)$.

\subsubsection{Cavity formation and growth}

Cavitation is a general term used to describe the formation of bubbles in a moving liquid. Shi et al. [8] have used experimental visualization to describe this phenomenon. They shot projectiles vertically into a tank filled with water and used a shadowgraph system to visualize cavitation.

As a projectile moves through a liquid, a pressure differential exists between the head (static pressure $p_{0}$ ) and the wake of the projectile. If the pressure in the wake reaches the vapor pressure of the liquid $\left(p_{v}\right)$, bubbles can form. Note that $u_{p}$ has an important value compare to $p_{v}$ and $p_{0}$ which implies cavitation parameter $K$ decreases, and the cavity diameter increases. This phenomenon is called supercavitation by Knapp et al. [9]. An analytical description has been proposed by Batchelor [10] and by Knapp et al. [9]:

$K=\frac{p_{0}-p_{v}}{\frac{1}{2} \rho_{l} u_{p}^{2}}$

Supercavitation is expected to influence the drag force applied to the solid body, compared to one without cavitation. As cited by Shi et al. [8], Batchelor proposed a linear approximation for the drag coefficient of an underwater body in an axially symmetric flow:

$C_{x}(K)=C_{x}(0)(1+K)$

It is assumed that (6) is valid for low $K$ values. For a high-velocity projectile (up to $1000 \mathrm{~m} \mathrm{~s}^{-1}$ ) shot into an atmospheric tank filled with water, the ratio between the static vapor pressure and the dynamic pressure becomes small $\left(\approx 10^{-6}\right)$. In such cases, cavity

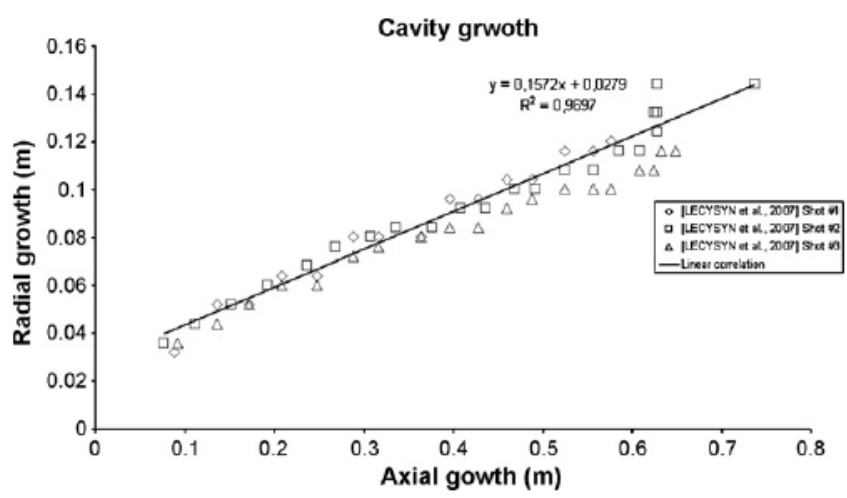

Fig. 3. Axial and radial growth of cavities.

dimensions also influence the hydraulic ram. Indeed, the formation and growth of a gas phase in the tank increases the pressure, which contributes to violent ejection of liquid from the tank.

Self and Ripken, as cited by Knapp et al. [9], have studied supercavitation to emphasize the relation between cavity dimensions and the cavitation parameter $K$. Reichardt [11], cited by Knapp et al. [9], found this relation between drag and cavity diameter:

$\frac{d_{\max }}{d_{p}}=\sqrt{\frac{C_{x}(K)}{K\left(1-0.132 K^{1 / 2}\right)}}$

This semi-empirical relation shows that when $K$ is small, cavity dimensions are large, and then the gas phase created in the tank is important; in fact, the result can be catastrophic ejection of liquid through the breach formed by projectile impact.

Held [12] has proposed a model, initially found by Szendrei [13], that applies to supercavitation induced by a jet-shaped charge in a liquid-filled target. The Bernoulli relation can be used to relate the static pressure $p$ to the axial growth velocity of a cavity:

$p=\frac{\rho_{l} u^{2}}{2}+\rho_{l} g h$

Szendrei [13] assumed that the axial growth velocity is the same as the radial one. This has been experimentally checked (Fig. 3). Rearranging (8), the radial growth velocity of the cavity can be expressed as

$\frac{d r_{c}}{d t}=u_{c} \approx u=\sqrt{\frac{2 p}{\rho_{l}}-2 g h}$

Although $p$ changes as the projectile penetrates the liquid, Szendrei [13] assumed that the force $\left(p A_{c}\right)$ applied to the projectile remains constant; then,

$p=p_{0} \cdot \frac{A_{p}}{A_{c}} \approx p_{0} \frac{d_{p}^{2}}{4 r_{c}^{2}}$

If $p_{0}$ is the initial static pressure, its value is hardly as large as the pressure of the static undisturbed liquid, which can be neglected. So, applying the Bernoulli relation,

$p=\frac{\rho_{p}\left(u_{p 0}-u_{c}\right)^{2}}{2}$

Held [12] assumed that the cavity growth velocity is proportional to the projectile velocity,

$u_{c}=\frac{u_{p}}{1+\sqrt{\rho_{l} / \rho_{p}}}$ 


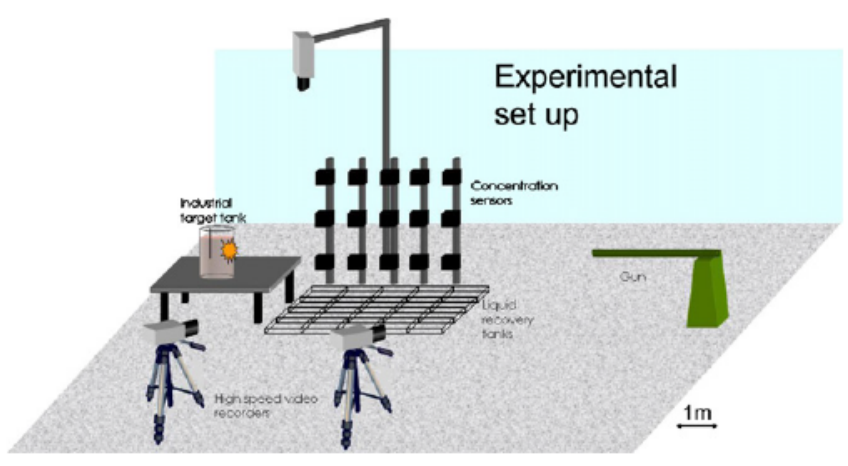

Fig. 4. Experimental setup for the DGA tests.

This hypothesis applies in this case (Fig. 3), so combining (10), (11) and (12) gives

$p=\frac{d_{p}^{2} \rho_{l} u_{p}^{2}}{8 r_{c}^{2}\left(1+\sqrt{\rho_{l} / \rho_{p}}\right)^{2}}$

Substituting this expression for $p$ into (9), we find

$\frac{\mathrm{d} r_{c}}{\mathrm{~d} t}=\sqrt{\frac{d_{p}^{2} u_{p}^{2}}{4 r_{c}^{2}\left(1+\sqrt{\rho_{l} / \rho_{p}}\right)^{2}}-g h}=\sqrt{A \frac{u_{p}^{2}}{r_{c}^{2}}-2 g h}$

The projectile velocity is given analytically by (4), which we now write as

$u_{p}=\frac{u_{p 0}}{1+\left(3 u_{p 0} C_{x} \rho_{l} / 4 \rho_{p} d_{p}\right) t}=\frac{u_{p 0}}{1+B t}$

So combining (15) with (14) leaves

$\frac{d r_{c}}{d t}=\sqrt{A \frac{u_{p 0}^{2}}{r_{c}^{2}(1+B t)^{2}}-2 g h}$

where $A$ and $B$ are given by

$A=\frac{d_{p}^{2}}{4\left(1+\sqrt{\rho_{l} / \rho_{p}}\right)^{2}}$

$B=\frac{3 u_{p 0} C_{x} \rho_{l}}{4 \rho_{p} d_{p}}$

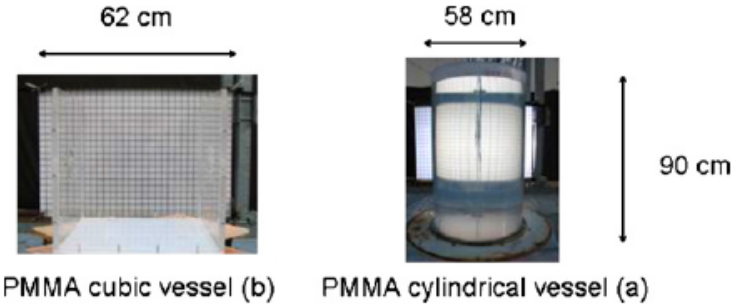

Fig. 5. Cylindrical (a) and cubic (b) target vessels with visualization screens.

Finally, applying Euler's finite-difference relation for small $\Delta t,(16)$ can be written as

$r_{c}(t+d t)=r_{c}(t)+\sqrt{A \frac{u_{p 0}^{2}}{r_{c}^{2}(1+B t)^{2}}-2 g h . \Delta t}$

\section{Apparatus and methods}

\subsection{Experimental device}

Tests were performed in which a high-velocity projectile impacted a liquid-filled tank. A gun was used to accelerate a small spherical projectile and a high-speed recording device (from 4000 to 50,000 frames per second (fps) with ammonium hydroxide (Table 1)) was used to record the progress of the projectile through the liquid. The experimental setup is illustrated in Fig. 4. This experimental device is largely detailed in [16] (Figs. 5-7).

\subsection{Projectile velocity measurement}

Video sequences were processed to enhance images of projectile displacement [17]; the enhancements consisted of filtering, eroding, and thresholding each image of shotgun sequences. The exposure time $(1 / 30,000 \mathrm{~s})$ of the camera was long enough (compared to the time of flight of the projectile) to record an "optical smear" (Fig. 8). The length of the "optical smear" divided by the time between two frames $(30,000 \mathrm{fps})$ provides the projectile velocity. The accuracy of this procedure depends on the optical aberrations described in the previous section.

Therefore, we were able to obtain projectile velocities both before and after impact, thereby obtaining the decay of velocity in the vessel. Note, however, that the projectile velocity was not mea-
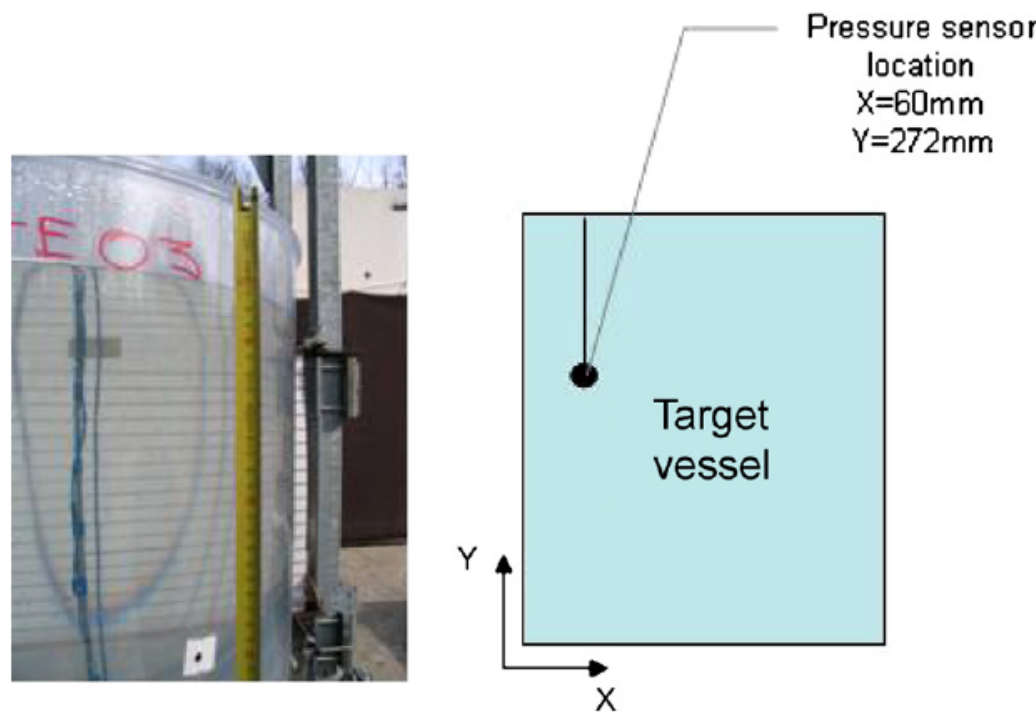

Fig. 6. Position of pressure sensors in targets. 


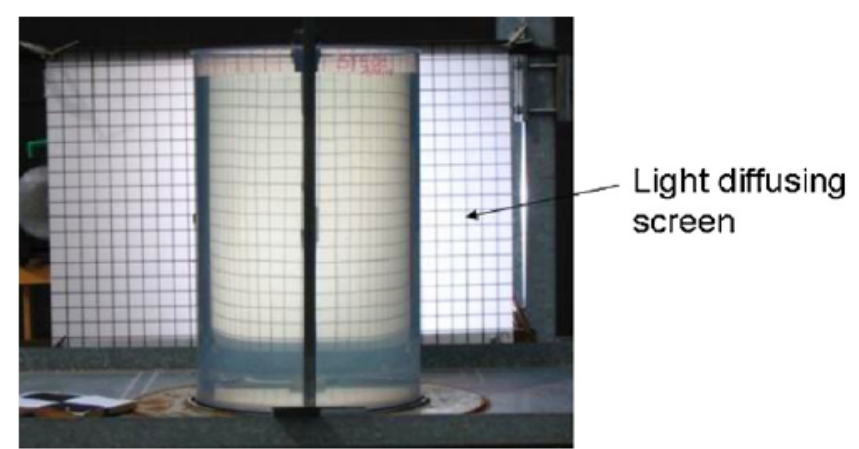

Fig. 7. Light-diffusing screen and top camera.
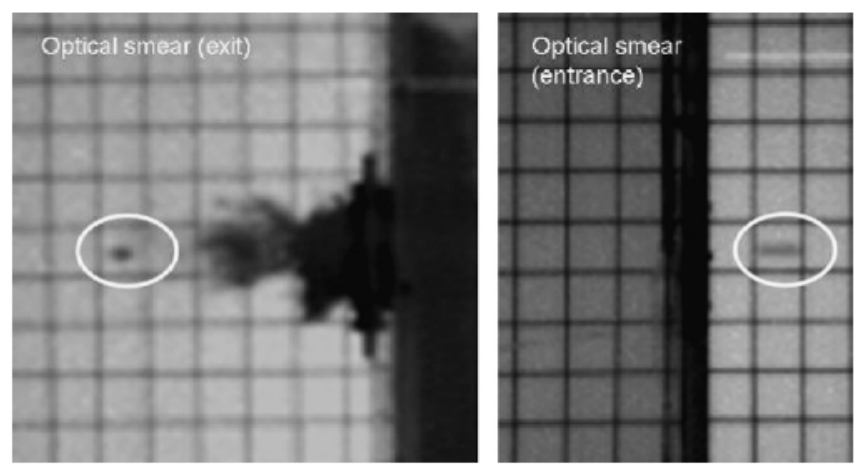

Fig. 8. Optical measurement of projectile velocity. At right is a projectile about to enter the target, at left the projectile is leaving the tank.

sured in the liquid because such measurements would be affected by optical refraction from the liquid and from the transparent walls; in cylindrical vessels, velocity measurements in the liquid would be further degraded by refraction from the circular walls. Instead, the average velocities of projectiles were measured in air, where energy loss due to drag is insignificant compared to deceleration in the liquid (for very short time intervals). Consequently, the experimental velocities obtained from this optical technique are the initial and final velocities of the projectile crossing the tank.

\subsection{Cavity growth measurement}

Cavitation crater diameters were measured from high-speed imaging records (Fig. 9). To quantify the experimental uncertainty, light refraction was taken into account, as shown in Fig. 10,

$n_{1} \sin \theta_{1}=n_{2} \sin \theta_{2}$

Fig. 11 shows a two-dimensional interpretation of light refraction during these tests. Note that the longer the path followed by light through the tank wall, the more a light ray diverges. Consequently, the error due to refraction is minimized for points along the target symmetry axis and maximized for points close to the walls. However, the distance from the camera $(d)$ to the target is large

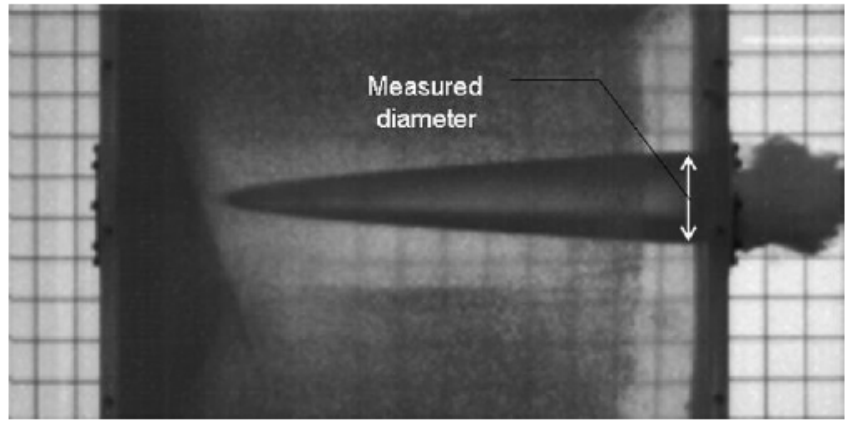

Fig. 9. Measuring the growth in diameter of a cavity.

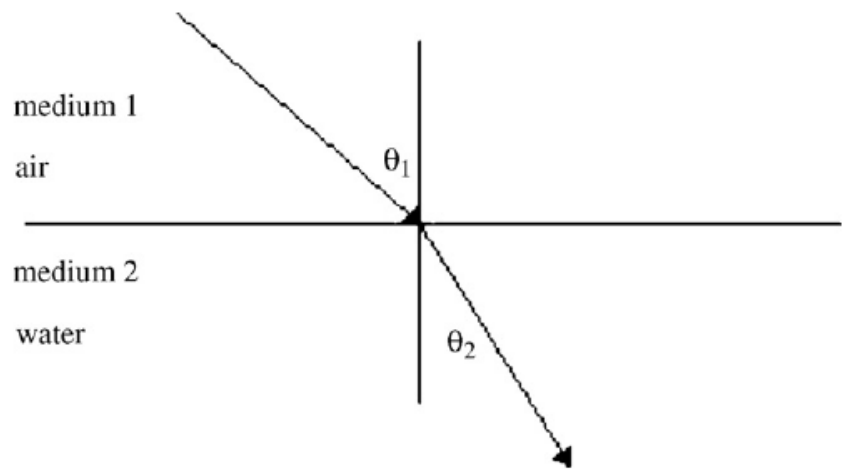

Fig. 10. Schematic of light being refracted as it leaves one medium and enters another.

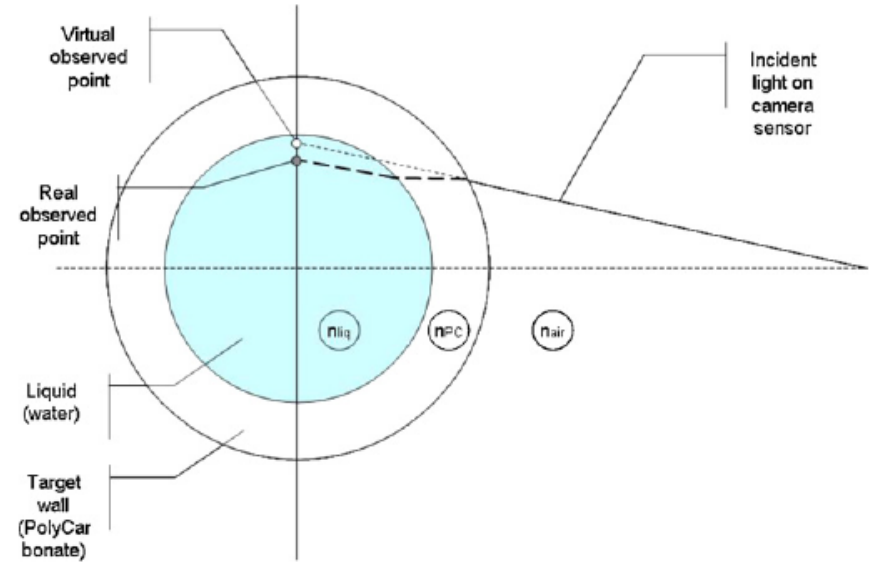

Fig. 11. Top-view schematic showing refracted light as observed by camera (adapted from Serradeill [22]).

compared to the diameter $(\Phi)$ of the tank, and the ratio can be expressed by

$\frac{\Phi}{d}=\frac{500}{8540}=6 \times 10^{-2} \approx \frac{\sin \theta_{2}}{\sin \theta_{1}} \Rightarrow \theta_{1} \gg \theta_{2}$ (a)

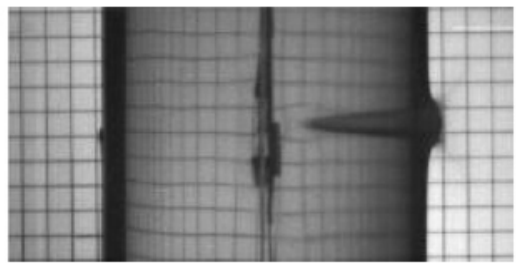

(b)

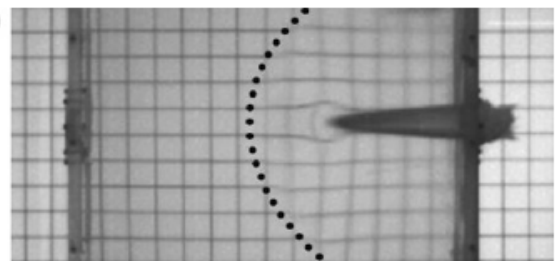

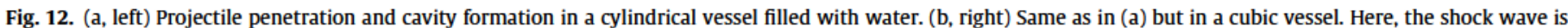
clealy visible. In both cases the initial projectile velocity was $1255 \mathrm{~m} \mathrm{~s}^{-1}$. 
(a)

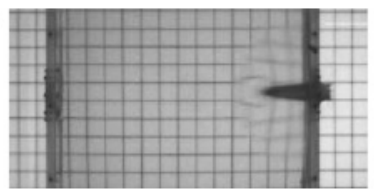

(b)

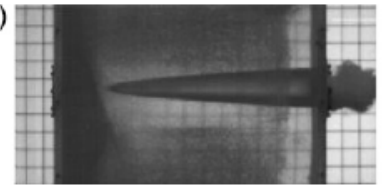

(c)

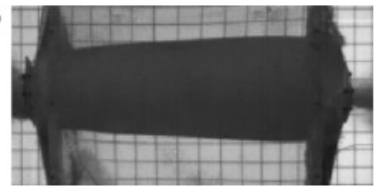

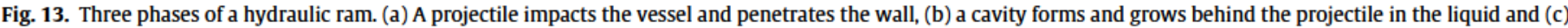
the cavity continues to grow even after the projectile has exited the tank. Here the initial velocity of the projectile was $1255 \mathrm{~m} \mathrm{~s}^{-1}$.

Consequently, the estimated error is about $6 \%$, to which optical aberrations (2\%) must be added.

\section{Results and discussion}

\subsection{Description of the phenomena}

Using the videos recorded during each test, such as in Fig. 12, we can identify the following phases of the phenomenon: (a) the projectile impacts the vessel,(b) the projectile penetrates the vessel wall and a hydraulic ram begins to form (Fig. 12a), (c) the projectile crosses the vessel in about $800 \mu$ s and during this time a cavity forms (Fig. 12b) and (d) the cavity grows over a period of about $5 \mathrm{~ms}$ (Fig. 12c).

Shortly after impact, Fig. 13a shows a shock wave forming in front of the projectile and beginning to propagate through the liquid. The optical diffraction of the grid shadow shows that liquid is perturbed by the shock wave, which moves at $c_{l}>u_{p}$. Then a cavity forms behind the projectile (Fig. 12b); this is caused by air from the atmosphere which is entrained by the projectile [8]. The volume of this cavity increases quickly, perturbing thermodynamic equilibrium [9] and creating a negative pressure with a consequent air vacuum in the cavity [18]. Now projectile drag creates a pressure differential between the front and rear of projectile. When the pressure at the rear of the projectile reaches the liquid vapor pressure, the cavity is further enlarged. Another significant phenomenon occurs when the projectile enters the liquid: a splash forms at the liquid boundary on both sides of the vessel (Fig. 12c). This is attributed to the added mass of air and overpressure in the vessel, which leads to ejection of liquid through both the entry and exit holes.

Cavity growth by air entrainment continues until the diameter is about $0.2 \mathrm{~m}$, which is about twenty times more than the projectile diameter. Then, after the projectile has crossed the liquid, cavity growth continues until the diameter is about $0.5 \mathrm{~m}$, which is half the height of the vessel.

It is worth noting that no oscillations (collapse and rebound of cavity in the wake of projectile) have been identified in this study, although this phenomenon is classically detected like in [24]. That fact is probably due to exposure time and pressure transducers location, not appropriate to visualize or record this oscillation.

\subsection{Projectile velocity loss}

The model proposed by Stepka et al. [1] for loss of projectile velocity is compared to experimental points in Fig. 14. In this case, values for $C_{x}$ have been computed using the Brauer relation [19]:

$C_{x}=\frac{24}{\operatorname{Re}}+\frac{3,73}{\sqrt{\operatorname{Re}}}-\frac{4.83 \times 10^{-3} \sqrt{\mathrm{Re}}}{1+3 \times 10^{-6} \mathrm{Re}^{3 / 2}}+0.49$

Cavitation drag has not been taken into account for projectile velocity decay, which seems to be sufficient to explain the phenomenon. It is assumed that the cavitation parameter is very small; this point is developed in Section 3.3.

In Fig. 14, the projectile velocity is plotted as a ratio of initial to final velocities and the independent variable is taken to be the dimensionless impact parameter $\left(C_{x} \rho_{l} u_{p 0} t\right) /\left(\rho_{p} d_{p}\right)$, as proposed by Stepka et al. [1]. Experimental points were computed from optically measured velocities for $u_{p 0}$ and $C_{x}$, liquid densities and viscosities were taken from [14] and [15]. Eq. (3) can be resolved over $x$, we have to introduce it like:

$\rho_{p} V_{p} \frac{d U_{p}}{d x} \frac{d x}{d t}=\rho_{p} V_{p} u_{p} \frac{d u_{p}}{d x}=-\frac{1}{2} C_{x} \rho_{l} A_{p} u_{p}^{2}$

Then separate variables and integrate over $x$ to obtain

$u_{p}(x)=u_{p 0} e^{\left(-3 C_{x} \rho_{l} x / 4 d_{p}\right)}$

Knowing the crossing length (tank dimensions reduced by walls thick) and the average projectile velocity given by (24), the crossing

\section{Projectile velocity decay}

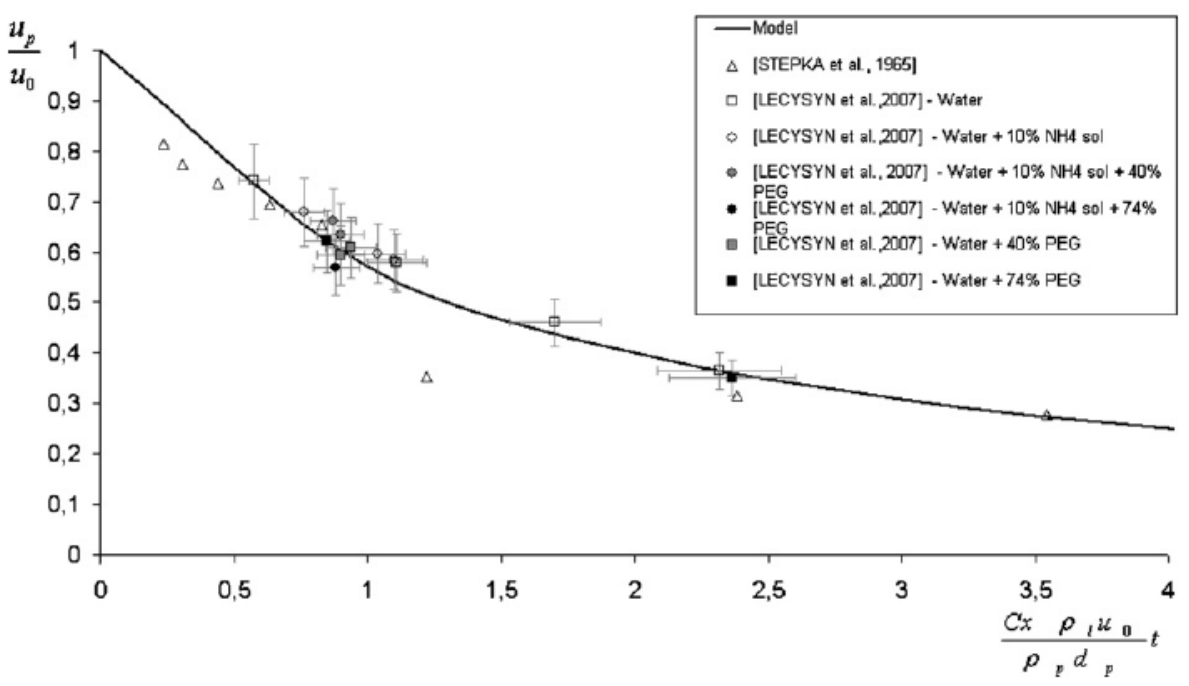

Fig. 14. Decay in projectile velocity as it crosses various target liquids. Error bars are $\pm 10 \%$ in both directions. 


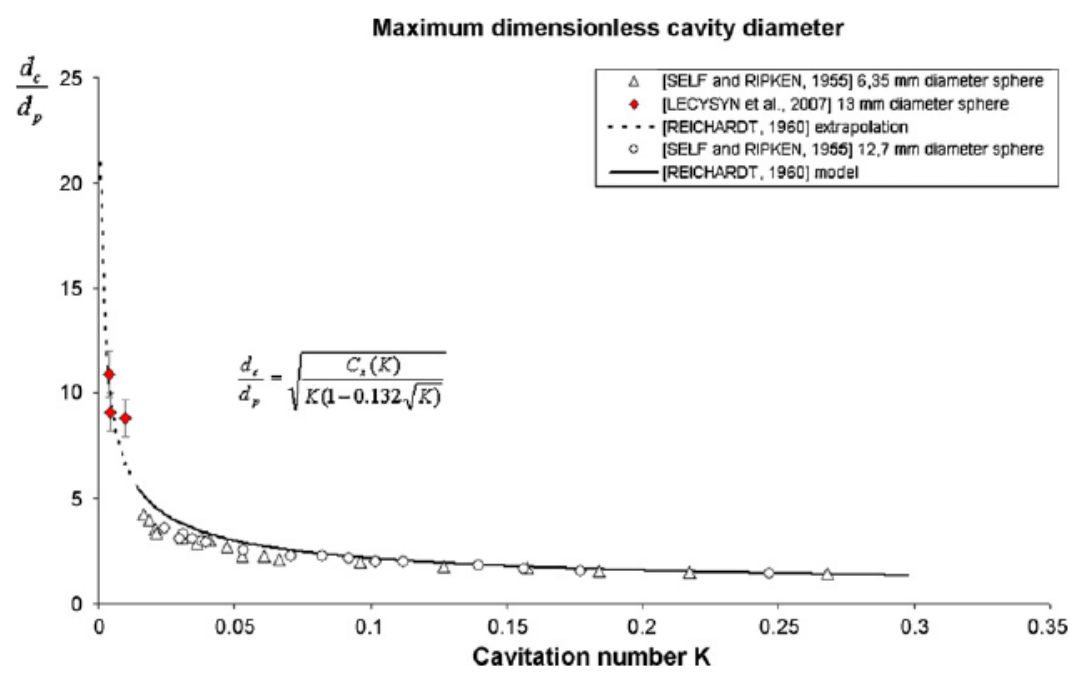

Fig. 15. Relation between cavity diameter and cavitation parameter.

Table 1

Density of ammonium hydroxide $\left(\mathrm{kg} \mathrm{m}^{-3}\right)$.

\begin{tabular}{|c|c|c|c|c|c|}
\hline \multirow[t]{2}{*}{ Ammonia mass fraction (\%) } & \multicolumn{5}{|c|}{ Temperature $\left({ }^{\circ} \mathrm{C}\right)$} \\
\hline & 0 & 5 & 10 & 20 & 25 \\
\hline 8 & 969.5 & 968.6 & 967.7 & 965.1 & 964.0 \\
\hline 12 & 956.1 & 954.8 & 953.4 & 950.1 & 948.0 \\
\hline
\end{tabular}

time $t$ can be determined. The experimental points in Fig. 14 fit the model, which means that (3) is sufficient to explain the velocity decrease and, consequently, the transfer of kinetic energy to the liquid. In Fig. 14, the 10\% vertical error bars account for errors in the optical measurements (Section 2.2) and the 10\% horizontal bars account for uncertainties in liquid densities and viscosities.

\subsection{Cavitation}

Values for the cavitation parameter have been calculated using the static pressure at the axis level of the projectile path in the target $\left(\approx 3\left(\times 10^{3}\right) \mathrm{Pa}\right)$, the liquid vapor pressure $\left(\approx 2\left(\times 10^{3}\right) \mathrm{Pa}\right)$, and the dynamic pressure caused by liquid displacement in the vicinity of the projectile $\left(\approx 5\left(\times 10^{8}\right) \mathrm{Pa}\right)$; the results were small values for $K$ $\left(\approx 10^{-5}\right)$. This confirms the negligible influence of cavitation on the drag coefficient (5). However, Fig. 15 shows the relation between $K$ and cavity dimensions, as proposed in (7). Other studies on supercavitation performed by Self and Ripken [20] at lower velocities (12-15 $\mathrm{m} \mathrm{s}^{-1}$ ) have shown the validity of the semi-empirical relation proposed by Reichardt [11]. In this present study, we have extrapolated the model and reported our experimental points (Fig. 15), again confirming the validity of the model.

Another aspect of this study was to quantify the dynamics of the gas phase caused by supercavitation, for growth of the cavity is expected to contribute to ejection of liquid from the tank. Thus, Held's model [12] is compared to our experimental data in Fig. 16. The model predicts a rapid initial increase in cavity diameter which is attenuated after $200 \mu \mathrm{s}$. The experimental data fit the model well during the initial phase, but the data continue to increase at longer times while the model predicts that the growth rate slows. Optical refraction could be a source of uncertainties; however, note that air drag, described by Shi et al. [8], is not taken into account.

\subsection{Influence of cavitation on liquid discharge}

Preliminary investigations in 2005 (Figs. 17 and 18) suggested that cavitation affects liquid ejection morphology. The experi- mental setup, which is largely detailed in [16] and [21], involved shooting a high-velocity sphere (velocities close to $1000 \mathrm{~m} \mathrm{~s}^{-1}$ ) into industrial steel vessels filled with water or ammonium hydroxide. The aim of those experiments was to observe violent liquid ejection due to impact and tank failure. High-speed video recorders were used to visualize the phenomenon (Fig. 4).

Two important features were observed during the first $3 \mathrm{~ms}$ of liquid ejection (Fig. 17): (a) the cavity is visible and seems to influence initial liquid jet morphology and (b) the longitudinal shape of the breech does not have any effect at this time scale. Side views in Fig. 18 confirmed these observations: the initial liquid jet morphology looks like a snake's tongue and is circular. This is why we have tried to correlate cavitation diameter to the "snake tongue" diameter. Therefore, this model has been used to predict initial jet shape as described in Fig. 19.

Fig. 20 synthesizes experimental points from previous tests (2006 and 2007) in which the experimental setup was the same as that used in 2005 [21]. The correlation is not ideal, which can be explained by the fact that cavitation is not the only event contributing to initial jet morphology. Momentum exchange between the air phase and liquid jet is also expected to play a role. This has been studied more accurately in a numerical study that uses a two-dimensional multiphase model [23] (Table 2).

It is important to note that these tests series allow studying the phenomenon at small scale compared to larger tanks in an industrial place. Two elements of discussion can be found in [16]:

- A dimensional study has shown that it is possible to analyze the problem thanks to a set of six non-dimensional numbers;

Table 2

PEG 400 viscosity and density at $25^{\circ} \mathrm{C}$.

\begin{tabular}{lcl}
\hline PEG 400 mass fraction (\%) & Viscosity (mPas) & Density $\left(\mathrm{kg} \mathrm{m}^{-3}\right)$ \\
\hline 40 & 4.83 & 1065.5 \\
74 & 23.66 & 1121.5 \\
\hline
\end{tabular}



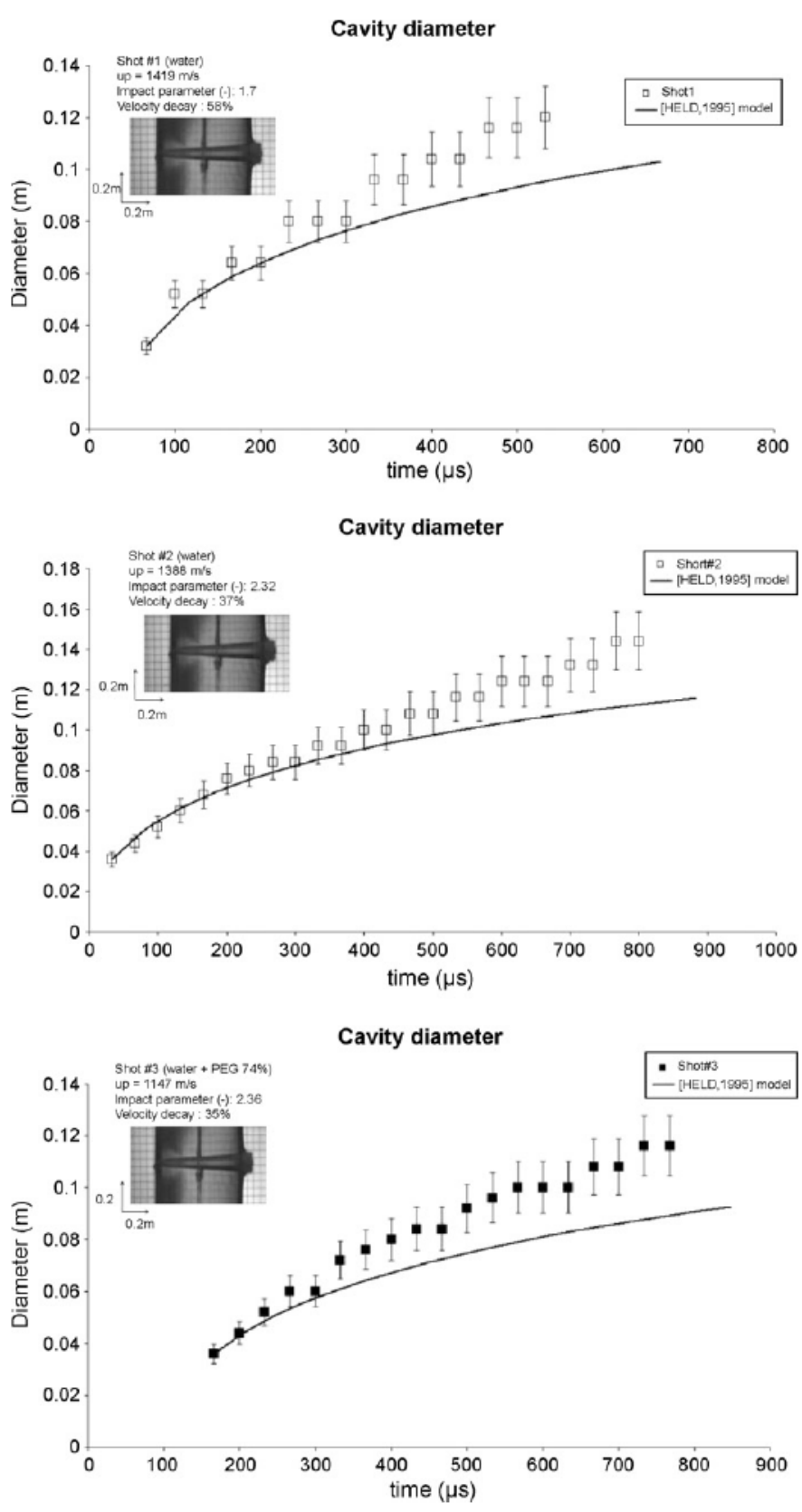

Fig. 16. Growth in cavity diameter over time. (top) Target was water and projectile had an initial velocity of $1419 \mathrm{~m} \mathrm{~s}^{-1}$. (middle) Target was water and projectile had an initial velocity of $1388 \mathrm{~m} \mathrm{~s}^{-1}$. (bottom) Target was 74\% PEG in water and projectile had an initial velocity of $1147 \mathrm{~m} \mathrm{~s}^{-1}$. Points are experimental data and lines are the model developed by Held [12]

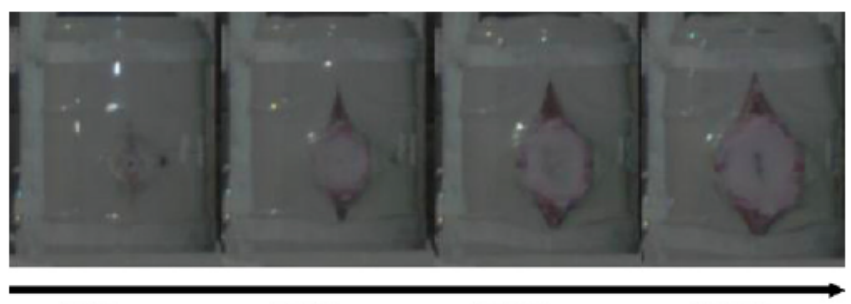

$667 \mu \mathrm{s}$

$1500 \mu \mathrm{s}$

$2333 \mu s$

$3167 \mu \mathrm{s}$

Fig. 17. Front view of first $3 \mathrm{~ms}$ of projectile exiting a liquid-filled tank.

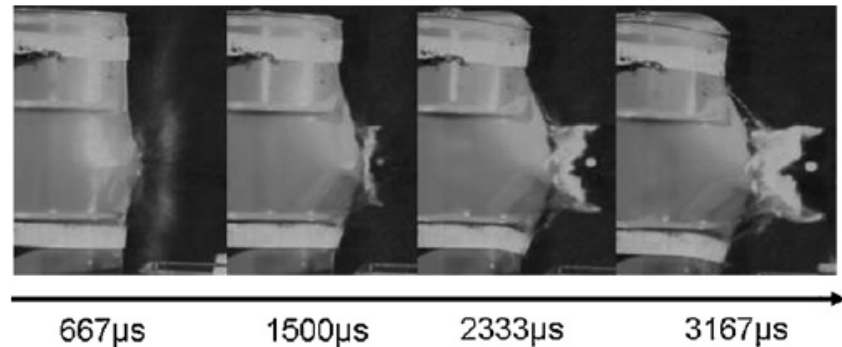

Fig. 18. Same experiment shown in Fig. 17, but viewed from the side. The liquid being ejected from the exit hole has the shape of a snake's tongue.

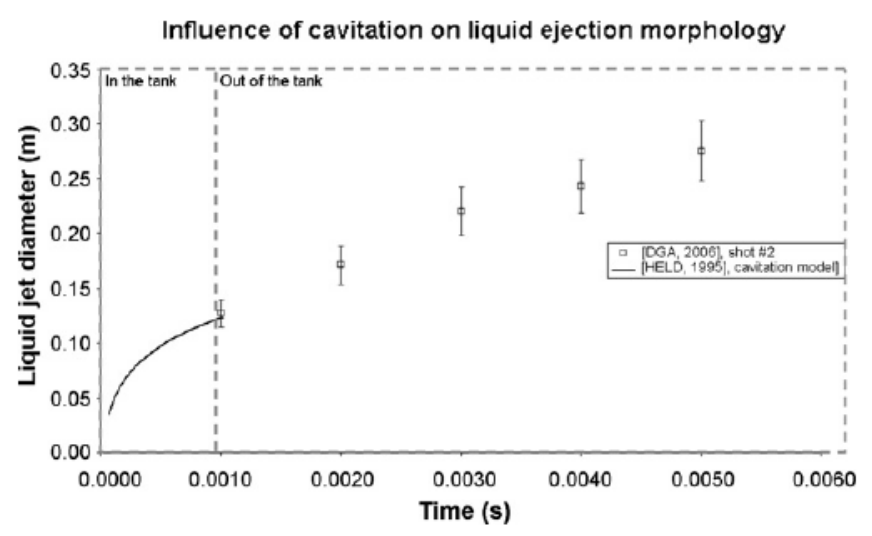

Fig. 19. Growth in diameter of jet ejecting liquid from projectile exit hole.

Influence of cavitation on liquid ejection morphology

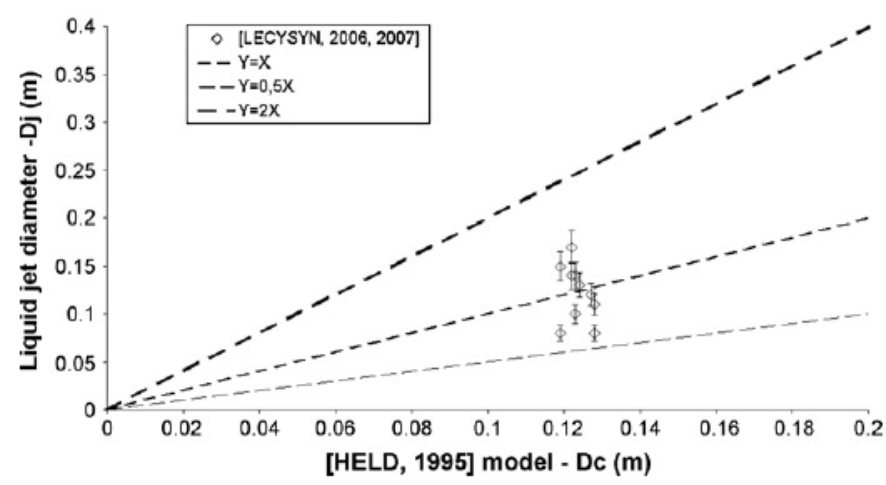

Fig. 20. Attempt to correlate cavity diameter (model) with diameter of jet (experiment) ejecting liquid from projectile exit hole.

- Numerical simulations could be a way to compute consequences from this analytical source term approach.

\subsection{Hydraulic ram}

Overpressure has been experimentally measured using the immersed pressure probes; values are reported in Table 3 . In Fig. 21 a linear correlation is proposed for relating experimental values to the calculated shock pressure. Such a linear relation, does exist between theoretical and experimental values, as published by Townsend et al. [6]. The experimental approach used in [6] consisted of measuring overpressure (at different points in the target) induced by a steel projectile on an aluminum tank filled with water. 
Table 3

Velocity and pressure values measured during DGA tests.

\begin{tabular}{|c|c|c|c|}
\hline Projectile velocity $\left(\mathrm{m} \mathrm{s}^{-1}\right)$ & Target & $P_{\max }(\mathrm{bar})$ & Time after impact $(\mu s)^{\mathrm{a}}$ \\
\hline 941 & Steel vessel filled with water (60l) & 116 & 129 \\
\hline 1460 & Steel vessel filled with water $(60 \mathrm{l})+10 \%$ ammonium hydroxide & $>380$ & 110 \\
\hline 971 & Steel vessel filled with water $(60 \mathrm{l})+10 \%$ ammonium hydroxide $+40 \%$ PEG & 104 & 109 \\
\hline 1273 & Steel vessel filled with water $(60 \mathrm{l})+10 \%$ ammonium hydroxide $+40 \%$ PEG & 195 & 139 \\
\hline 963 & Steel vessel filled with water $(60 \mathrm{l})+10 \%$ ammonium hydroxide $+74 \%$ PEG & 102 & 116 \\
\hline 1215 & Steel vessel filled with water (60l) & 291 & 117 \\
\hline 1241 & Steel vessel filled with water $(60 l)+10 \%$ ammonium hydroxide & 264 & 121 \\
\hline
\end{tabular}

a This value does not take account of accelerometer (MURATA PKS) response time which is about $\pm 20 \mu s$.

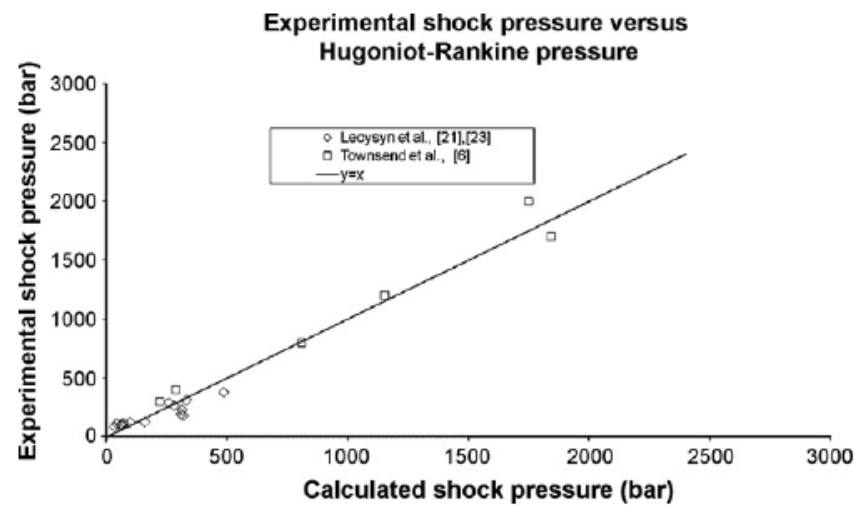

Fig. 21. Comparison of calculated and experimental shock pressures.

\section{Conclusions}

Tests were performed to reproduce and analyze the consequences of high-speed impacts of projectiles on fluid-filled tanks. Target-projectile interactions can be explained as a series of three events: shock-wave propagation, cavity formation, and energy loss.

Each of these events have can be analytically modeled by relations based on Hugoniot-Rankine, Newton's second law and Bernoulli relation.

It has been shown that these models depend on nondimensional numbers such as Reynolds, cavitation parameter, drag coefficient. For this set of experimental values, the models have been validated by experimental data and lead to the following conclusions

We expect that analytic descriptions of the phenomena will be improved by coupling these experimental results to CFD simulations. For example, such simulations should help us model cavity formation, shock-wave propagation, and dissipation of kinetic energy from the projectile into the liquid. The results were catastrophic failures of the vessels, and our studies have produced a preliminary step to understand the following liquid discharge.

In future work, we plan to characterize liquid discharge, fragmentation mechanisms, and subsequent evaporation of vessel contents. The overall goal is to attain an integrated description that starts from projectile impact and extends to consequences in terms of container failure, catastrophic liquid discharge, and final breakup [23] leading to evaporation and atmospheric dispersion (cloud concentrations).

\section{Acknowledgment}

The authors are grateful to CEG (Centre d'Etudes de Gramat) for their financial support and for their efficient help during the tests.

\section{References}

[1] F.S. Stepka, C.R. Morse, R.P. Dengler, Investigation of Characteristics of Pressure Waves Generated in Water Filled Tanks Impacted by High-velocity Projectiles, TN D-3143, 1965.

[2] R.E. Ball, Structural Response of Fluid-containing-tank to Penetrating Projectiles (Hydraulic Ram)-A Comparison of Experimental and Analytical Results, NPS-57Bp76051, 1976.

[3] P.D. Holm, Hydraulic Ram Shock Wave and Cavitation Effects on Aircraft Fuel Cell Survivability, 1973.

[4] E.A. Lundstrom, W.K. Fung, Fluid Dynamic Analysis of Hydraulic Ram III (Result of Analysis), JTCG/AS-74-T-015, 1976.

[5] L.S. Mueller, Experimental Investigation of Hydraulic Ram, 1974.

[6] D. Townsend, N. Park, P.M. Devall, Failure of fluid filled structures due to high velocity fragment impact, International Journal of Impact Engineering 29 (2003) 723-733.

[7] J.P. Borg, J.R. Cogar, S. Tredways, J. Yagla, M. Zwiener, Damage resulting from high speed projectile liquid filled metal tanks, in: Computational Methods and Experimental Measurements X, Wassex Institute of Technologies Press, 2001, pp. 889-902.

[8] H.H. Shi, I. Motoyuki, T. Takuya, Optical observation of the supercavitation induced by high-speed water entry, Transactions of the ASME 122 (2000) 806-810.

[9] R.T. Knapp, J.W. Daily, F.G. Hammit, Cavitation (1970) 196-197.

[10] G.K. Batchelor, An Introduction to Fluid Dynamics, 1967.

[11] H. Reichardt, The Laws of Cavitation Bubbles at Axially Symmetric Bodies in a Flow, Ministry of Aircraft Production (Britain), 1946, rep. and transl. 766.

[12] M. Held, Verification of the equation for radial crater growth by shaped charge jet penetration, International Journal of Impact Engineering 17 (1995)387-398.

[13] T. Szendrei, Analytical model of crater formation by jet impact and its application to calculation of penetration curves and hole profiles, in: Proceedings of the 8th International Symposium on Ballistics, vol. VII, 1983, pp. 39-47.

[14] A. Yurqina, M.E. Manzur, P. Brito, R. Manzo, M.A.A. Molina, Physicochemical studies of acetaminophen in water-Peg 400 systems, Journal of Molecular Liquids $133(1-3)(2007)$ 47-53.

[15] S. Kirincic, C. Klofutar, Viscosity of aqueous solutions of poly(ethylene glycol)s at 298.15 K, Fluid Phase Equilibria (1999) 155-311.

[16] N. Lecysyn, A. Dandrieux, F. Heymes, L. Aprin, P. Slangen, L. Munier, E. Lapebie, C. Le Gallic, G. Dusserre, Ballistic impact on an industrial tank: study and modelling of consequences, Journal of Hazardous Material 172 (2-3) (2009) 587-594.

[17] N. Lecysyn, P. Slangen, G. Dusserre, L Munier, E. Lapebie, C. Le Gallic, Experimental investigation of a catastrophic tank failure with a high speed video recorder. image processing and hydrodynamic characterization of the liquid jet, in: Proceedings of the 12th International Symposium Loss prevention and Safety Promotion in the Process Industries, Edinburgh, Scotland, Topic 4, Paper 212, 2007.

[18] H.I. Abelson, Pressure measurements in water-entry cavity, Journal of Fluid Mechanics 44 (1970) 129-144.

[19] N. Midoux, Mécanique et Rhéologie des Fluides en Génie Chimique, $3^{\text {ème }}$ tirage, 1993, p. 380.

[20] M. Self, J.F. Ripken, Steady-State Cavity Studies in a Free-Jet Water Tunnel, St Anthony Falls Hydr. Lab., 1955, Rep.47, July.

[21] F. Heymes, A. Bony-Dandrieux, N. Lecysyn, R. Spinelli, G. Dusserre, Etude de la Dispersion Atmosphérique d'un Polluant lors de la Destruction d'un Stockage, Rapport Final, Convention ARMINES N ${ }^{\circ} 40827,2006,87 p$.

[22] R. Serradeill, Effets Collatéraux-Essais 2003, T2004-00019/CEG/N, 2003, p. 46.

[23] N. Lecysyn, A. Dandrieux, F. Heymes, L Aprin, P. Slangen, L. Munier, C. Le Gallic, G. Dusserre, Ballistic impact on an industrial tank: study and modelling of consequences, Journal of Hazardous Materials 172 (December (2-3)) (2009) 587-594.

[24] D. Varas, J. López-Puente, R. Zaera, Experimental analysis of fluid-filled aluminium tubes subjected to high-velocity impact, International Journal of Impact Engineering 36 (2009) 81-91. 